nephron

Practice
Nephron 2015;131:118-122

DOI: $10.1159 / 000439387$
Received: May 21, 2015

Accepted: June 29, 2015

Published online: September 8, 2015

\title{
Acute Kidney Injury in the Surgical Patient: Recognition and Attribution
}

\author{
Azra Bihorac \\ Department of Anesthesiology, University of Florida, Gainesville, Fla., USA
}

\section{Key Words}

Acute kidney injury · Major surgery · Perioperative risk stratification · Intraoperative optimization · Postoperative complications

\section{Abstract}

Postoperative acute kidney injury (AKI) is not only one of the most common postoperative complications but is also associated with increased in-hospital mortality, decreased survival for up to 10 years after surgery and an increased risk for progression to chronic kidney disease and hemodialysis. Most of the studies that have developed clinically applicable risk models for prediction of AKI have focused on the most severe stages of AKI and rarely on less severe stages defined by consensus definitions. Furthermore, although multiple physiological signals are continuously recorded as a part of intraoperative management, their use for the development of risk models for AKI has been limited. Accurate risk stratification of patients in real time would enable the selection of optimal therapy in a timely fashion to prevent AKI altogether, or to mitigate the effects of the complication even before symptoms arise and can be tailored to a patients' personal clinical profile.

๑) 2015 S. Karger AG, Basel

\section{Epidemiology of Postoperative Acute Kidney Injury}

In the United States, where the average American can expect to undergo 7 surgical operations during her lifetime, each year at least 150,000 patients die and 1.5 million develop a medical complication within 30 days after surgery [1]. In addition to causing a 2 -fold increase in 30 day mortality and incurring an annual cost of $\$ 25$ billion $[1,2]$, postoperative complications are associated with long-term negative consequences. Postoperative acute kidney injury (AKI), characterized by a decrease in kidney function ranging from a mild decrease in glomerular filtration to complete renal failure, can affect up to $40 \%$ of surgical patients. Even if AKI resolves completely, it is associated with increased risks for chronic kidney disease, hemodialysis and death years after surgery [3-11].

Prior to 2004, the reported prevalence of hospital-acquired AKI varied significantly from 1 to $31 \%$ due to the incoherent criteria used to define AKI. With the intro-

Contribution from the AKI \& CRRT 2015 Symposium at the 20th International Conference on Advances in Critical Care Nephrology, Manchester Grand Hyatt, San Diego, Calif., USA, February 17-20, 2015.

\section{KARGER 125}

() 2015 S. Karger AG, Base

$1660-8151 / 15 / 1312-0118 \$ 39.50 / 0$

E-Mail karger@karger.com

www.karger.com/nef
Dr. Azra Bihorac

Department of Anesthesiology, University of Florida

1600 SW Archer Road, PO Box 100254

Gainesville, FL 32610-0254 (USA)

E-Mail abihorac@anest.ufl.edu 
duction of the AKI definition given by the Risk, Injury, Failure, Loss and End-stage Kidney (RIFLE) consensus, the importance of less severe AKI has been increasingly recognized [12]. The RIFLE guidelines define 3 grades of AKI severity based on at least a $50 \%$ change in serum creatinine relative to a reference value [13] and the recent consensus Kidney Disease: Improving Global Outcomes (KDIGO) guidelines have expanded the RIFLE criteria to include creatinine changes as small as $0.3 \mathrm{mg} / \mathrm{dl}$ [14]. The implementation of these consensus AKI definitions in the published surgical guidelines has been slow.

The American College of Surgeons Committee on Trauma defines AKI in trauma patients as a rise in serum creatinine above $3.5 \mathrm{mg} / \mathrm{dl}$, but in a multicenter trauma study evaluating prevalence of AKI defined by RIFLE criteria, only $15 \%$ of AKI patients had a serum creatinine value greater than $3 \mathrm{mg} / \mathrm{dl}$ [5]. The American College of Surgeons National Surgical Quality Improvement Program (ACS NSQIP), the largest prospective surgical database that quantifies 30-day risk-adjusted surgical outcomes for patients undergoing major surgical procedures [15], defines postoperative AKI as a postoperative rise in serum creatinine greater than $2 \mathrm{mg} / \mathrm{dl}$ or as the acute need for renal replacement therapy. To illustrate the lack of sensitivity of such a definition, consider that among patients with normal preoperative kidney function and creatinine in the range of $0.6-1.0 \mathrm{mg} / \mathrm{dl}$, AKI stage- 1 (defined by a $50 \%$ increase from baseline creatinine) would result in a postoperative serum creatinine change in the range of $0.3-0.5 \mathrm{mg} / \mathrm{dl}$ only. For the majority of elderly patients and women, whose baseline creatinine is expected to be $\leq 0.8 \mathrm{mg} / \mathrm{dl}$, even the most severe stage $3 \mathrm{AKI}$ with a 3 -fold increase in postoperative serum creatinine would result in $<1.6 \mathrm{mg} / \mathrm{dl}$ change from baseline, and thus would remain below the NSQIP cutoff of $2 \mathrm{mg} / \mathrm{dl}$. Two large studies using the ACS NSQIP data sets reported very low AKI prevalence, ranging between 1 and $1.6 \%$, with an 8 -fold increase in 30-day mortality $[16,17]$. In a single-center cohort study of over 20,000 surgical patients, comparison between the NSQIP and consensus definitions for AKI demonstrated that NSQIP captured only $7 \%$ of patients with AKI defined by consensus criteria. After applying the RIFLE definition to the $97 \%$ of patients with no AKI by NSQIP criteria, an additional $35 \%$ of the patients in the cohort were identified as having AKI and had a 5-fold increase in mortality compared to those with no AKI. Eighty percent of all 90day postoperative deaths occurred among patients with RIFLE AKI, although most of them had mild to moderate AKI only [3]. More importantly, the risk-adjusted asso-
Table 1. Risk-adjusted increase in hospital cost and mortality associated with postoperative AKI

\begin{tabular}{lcc}
\hline & $\begin{array}{l}\text { Risk-adjusted } \\
\text { relative cost } \\
\text { ratio }(95 \% \mathrm{CI})\end{array}$ & $\begin{array}{l}\text { Risk-adjusted } \\
\text { relative mortality } \\
\text { ratio }(95 \% \mathrm{CI})\end{array}$ \\
\hline $\begin{array}{l}\text { Patients with no AKI } \\
\text { Patients with any AKI }\end{array}$ & $\begin{array}{c}1.59(\text { reference) } \\
\text { AKI, stage }\end{array}$ & $\begin{array}{c}1 \text { (reference) } \\
\text { RIFLE-R }\end{array}$ \\
$\begin{array}{l}\text { RIFLE-I } \\
\text { RIFLE-F }\end{array}$ & $1.44(1.42-1.46)^{\mathrm{a}}$ & $1.71(1.41-2.08)^{\mathrm{a}}$ \\
\hline
\end{tabular}

The risk-adjusted relative cost and mortality ratios were derived using generalized linear models adjusted for age, gender, ethnicity, primary payer, Charlson comorbidity index, surgery type, emergent surgery status, weekend admission, estimated glomerular filtration rate and all postoperative complications.

${ }^{\mathrm{a}} \mathrm{p}$ value $<0.001$ using generalized linear models to compare with the non-AKI group. Adopted from Hobson et al. [21].

ciation between change in postoperative serum creatinine and various adverse clinical outcomes is continuous, and the complex association between magnitude and recovery of renal function plays a further role in determining the outcomes of patients with AKI [18]. The future studies in surgical population will need to address the issue of AKI staging among patients with very low baseline creatinine $(<0.6 \mathrm{mg} / \mathrm{dl})$ when urine output data is not available $[19,20]$. Contrary to the belief that postoperative AKI is a rare and fatal complication for which not much can be done in surgical patients, emerging evidence implies that AKI is a common and serious postoperative complication associated with increased risk for short and long-term mortality, other postoperative complications, resource utilization and cost (table 1) [3, 4, 21]. Increased awareness of the significance of AKI and the implications of not acting to prevent AKI in high-risk patients, or to facilitate renal recovery in established AKI, are costly and unacceptable.

\section{Risk Stratification for Postoperative AKI}

The risk for any postoperative complication, including $\mathrm{AKI}$, arises from the interactions between a patient's preoperative health and her physiologic capacity to withstand surgery-related stress, modulated by the type and quality of surgery that the patient undergoes. Knowing the extent to which preoperative health status predispos- 
Fig. 1. Relationship between intraoperative blood pressure and heart rate time series and risk for postoperative AKI defined by consensus criteria. Adopted from Bihorac et al. [30].

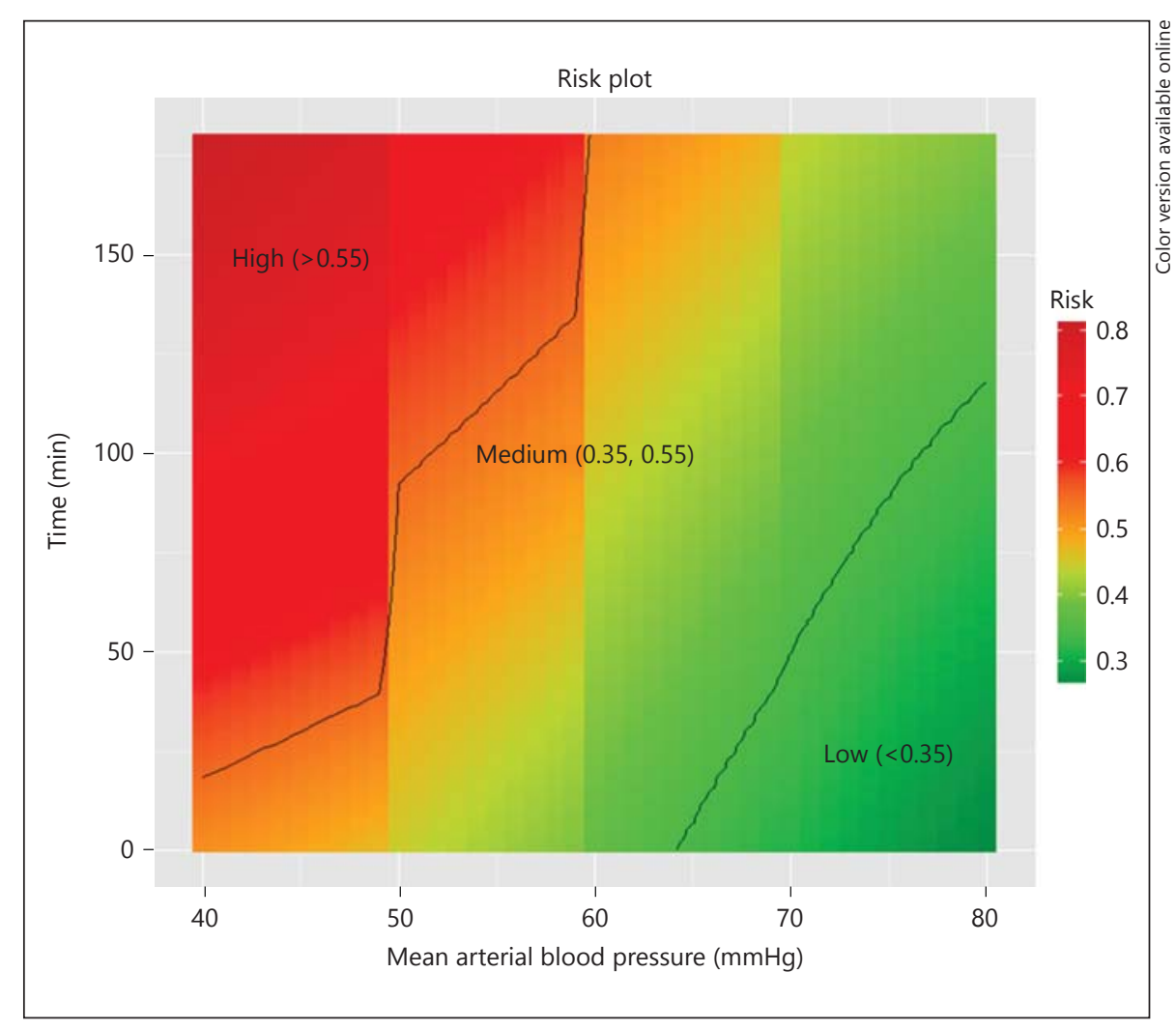

es a patient to the development of postoperative complications can facilitate a discussion between the patient and her physicians regarding the risks and benefits of surgery, and can decrease a patients' anxiety and uncertainty regarding outcomes. In the preoperative period, physicians need accurate risk assessment for AKI to timely identify those patients with the highest potential to benefit from protective therapies. Some of these therapies are not only costly but carry their own risks, like intraoperative goaldirected therapy or invasive hemodynamic monitoring.

The modification of intraoperative management appears to have an important effect on kidney function. A recent meta-analysis of 20 randomized controlled trials of perioperative hemodynamic monitoring identified several interventions that were associated with significant reduction in the incidence of all severity stages of AKI [22]. Optimizing intravascular volume, cardiac output or oxygen delivery in high-risk patients (those having emergency surgery, those with a higher revised cardiac risk index or a higher risk according to criteria of the American Society of Anesthesiologists and those aged $>60$ years) resulted in a decreased risk of perioperative AKI, both if started preoperatively (OR $0.70,95 \%$ CI $0.53-0.94 ; \mathrm{p}=0.02$ ) or intraoperatively (OR $0.47,95 \% \mathrm{CI}$
$0.27-0.81 ; p=0.006)$. Future studies related to the effects of intraoperative goal-directed therapy for AKI prevention are warranted. Other less costly interventions are easy and reasonable to implement if the risk is identified, like avoiding nephrotoxic contrast media and non-steroidal anti-inflammatory medications in patients with chronic kidney disease, and avoiding anesthetic techniques that may contribute to hemodynamic instability in high-risk patients [23]. All of these interventions are either often applied without consideration of a patient's preoperative risk or not applied at all because the risk is underestimated [24].

In the postoperative period, a patients' preoperative risk is modulated by their response to the events of surgery, often manifesting as subtle changes in physiologic parameters like blood pressure or heart rate. The physician's intraoperative management of hemodynamic status, sedation and mechanical ventilation directly affects surgery-related stress and can either exacerbate it or ameliorate it. With dynamic measurement of the risk for AKI, there will be the opportunity to initiate timely and appropriate preventive therapies, such as appropriate goal-directed fluid resuscitation and monitoring in the intensive care unit, for those patients who are judged to be at high 
risk of AKI. Similarly, if risk for AKI is judged to be low, patients may avoid exposure to unnecessary procedures and therapies.

Most of the studies for preoperative AKI risk stratification have been limited to a specific type of surgery or have used the occurrence of severe or dialysis-dependent AKI as an end point while excluding the more prevalent mild to moderate AKI. Studies on patients undergoing cardiac surgery reported predictive models for severe AKI with area under the receiver operating characteristic curve (AUROC) values up to $0.84[25,26]$. Among patients undergoing non-cardiac surgery data is limited to predictive scores for severe AKI only with the AUROC below 0.77 $[16,27]$.

The myriad of continuous physiologic data routinely acquired during intraoperative monitoring is rarely used in published risk scores and, when used, is usually summarized using a reductionist approach (such as mean or lowest value) rather than applied in their continuity and is almost never collected and analyzed in real time. With the advance of electronic health records, the ability to utilize the richness of clinical data collected as a part of routine care for the development of new diagnostic tools is dramatically increased. Novel approaches using machine learning algorithms based on automated, rapid, noninvasive measurements of cardiorespiratory physiology obtained in the operating room and intensive care unit will be applied to a range of risk prediction tasks to improve patient care and resource allocation. Using the readily available demographic, socioeconomic, comorbidity, intraoperative, laboratory and medication data, we have developed a computerized algorithm that calculates a probabilistic risk score for postoperative AKI defined by consensus criteria. The risk score ranged from 0 to 1 , with a high score indicating a high risk of AKI. The model had good performance with an overall AUROC of 0.87 , and 2 cutoff points ( 0.3 and 0.5 ) were used to identify those patients with low, medium and high risk for AKI. For patients with a preoperative risk score for $\mathrm{AKI} \geq 0.5$, the odds for developing postoperative AKI were 28 times higher (95\% CI 27-30) compared to patients with a low risk score of $<0.3$ (fig. 1) [24]. Future studies will require large data sets and prospective validation of this approach before clinical use.

A recently validated urinary biomarker for AKI, the product of the levels of tissue inhibitor of metalloproteinase 2 and insulin-like growth factor binding protein 7 (TIMP2*IGFBP7), provides a new tool to assess the risk of AKI in postoperative patients $[28,29]$. Patients with a urinary TIMP $2 *$ IGFBP7 level of $>0.3 \mathrm{ng} / \mathrm{ml}(2 / 1,000)$ had
7 times the risk for developing moderate to severe AKI within $12 \mathrm{~h}$ of the test compared to patients with urinary TIMP2*IGFBP7 level of $<0.3$. This is the first urinary biomarker approved by the US Food and Drug Administration for risk stratification of AKI in critically ill patients (NephroCheck ${ }^{\circledR}$ Test, Astute Medical, Inc., San Diego, Calif., USA). Although these studies did not specifically test postoperative patients, high-risk surgery and trauma were considered as risk factors for AKI allowing the inclusion of a significant proportion of surgical patients in both cohorts. The adequate identification of surgical patients who should undergo urinary (TIMP2*IGFBP7) test is critical, and validation of clinical risk stratification tools for this purpose is of great importance.

In summary, AKI significantly affects perioperative outcomes. AKI is a common complication after surgery, and mild to moderate AKI is more common than severe AKI. All stages of AKI severity are associated with increased short- and long-term morbidity and mortality. Clinical risk factors for AKI are similar but not identical in different surgical populations. Current strategies should focus on better management of the preoperative risks and susceptibilities for $\mathrm{AKI}$ and those intraoperative hemodynamic derangements that have been shown to impact renal function.

\section{Acknowledgments}

A.B. is supported by Center for Sepsis and Critical Illness Award P50 GM-111152 from the National Institute of General Medical Sciences and has received research grants from Society of Critical Care Medicine and Astute Medical, Inc.

\section{References}

1 Weiser TG, Regenbogen SE, Thompson KD, Haynes AB, Lipsitz SR, Berry WR, Gawande AA: An estimation of the global volume of surgery: a modelling strategy based on available data. Lancet 2008;372:139-144.

2 Khuri SF, Henderson WG, DePalma RG, Mosca C, Healey NA, Kumbhani DJ; Participants in the VA National Surgical Quality Improvement Program: Determinants of longterm survival after major surgery and the adverse effect of postoperative complications. Ann Surg 2005;242:326-341; discussion 341343.

3 Bihorac A, Brennan M, Ozrazgat-Baslanti T, Bozorgmehri S, Efron PA, Moore FA, Segal MS, Hobson CE: National surgical quality improvement program underestimates the risk associated with mild and moderate postoperative acute kidney injury. Crit Care Med 2013;41:2570-2583. 
4 van Kuijk JP, Flu WJ, Chonchol M, Hoeks SE, Winkel TA, Verhagen HJM, Bax JJ, Poldermans D: Temporary perioperative decline of renal function is an independent predictor for chronic kidney disease. Clin J Am Soc Nephrol 2010;5:1198-1204.

5 Bihorac A, Delano MJ, Schold JD, Lopez MC, Nathens AB, Maier RV, Layon AJ, Baker HV, Moldawer LL: Incidence, clinical predictors, genomics, and outcome of acute kidney injury among trauma patients. Ann Surg 2010; 252:158-165.

6 Hobson CE, Yavas S, Segal MS, Schold JD, Tribble CG, Layon AJ, Bihorac A: Acute kidney injury is associated with increased longterm mortality after cardiothoracic surgery. Circulation 2009;119:2444-2453.

7 Bihorac A, Yavas S, Subbiah S, Hobson CE, Schold JD, Gabrielli A, Layon AJ, Segal MS: Long-term risk of mortality and acute kidney injury during hospitalization after major surgery. Ann Surg 2009;249:851-858.

8 Ishani A, Nelson D, Clothier B, Schult T, Nugent S, Greer N, Slinin Y, Ensrud KE: The magnitude of acute serum creatinine increase after cardiac surgery and the risk of chronic kidney disease, progression of kidney disease, and death. Arch Intern Med 2011;171:226233.

9 Chawla LS, Amdur RL, Shaw AD, Faselis C, Palant CE, Kimmel PL: Association between $\mathrm{AKI}$ and long-term renal and cardiovascular outcomes in United States veterans. Clin J Am Soc Nephrol 2014;9:448-456.

10 Vaught A, Ozrazgat-Baslanti T, Javed A, Morgan L, Hobson C, Bihorac A: Acute kidney injury in major gynaecological surgery: an observational study. BJOG 2014, Epub ahead of print.

11 White LE, Hassoun HT, Bihorac A, Moore LJ, Sailors RM, McKinley BA, Valdivia A, Moore FA: Acute kidney injury is surprisingly common and a powerful predictor of mortality in surgical sepsis. J Trauma Acute Care Surg 2013;75:432-438.

12 Lameire NH, Bagga A, Cruz D, De Maeseneer J, Endre Z, Kellum JA, Liu KD, Mehta RL, Pannu N, Van Biesen W, Vanholder R: Acute kidney injury: an increasing global concern. Lancet 2013;382:170-179.
13 Bellomo R, Ronco C, Kellum JA, Mehta RL, Palevsky P; Acute Dialysis Quality Initiative Workgroup: Acute renal failure - definition, outcome measures, animal models, fluid therapy and information technology needs: the second international consensus conference of the acute dialysis quality initiative (ADQI) group. Crit Care 2004;8:R204-R212.

14 KDIGO Acute Kidney Injury Work Group: KDIGO clinical practice guideline for acute kidney injury. Kidney Int Suppl 2012;2:1-138.

15 American College of Surgeons: National surgical quality improvement program. Chicago, IL 60611-3211 American College of Surgeons, 2002-2012, 2013.

16 Kheterpal S, Tremper KK, Heung M, Rosenberg AL, Englesbe M, Shanks AM, Campbell DA Jr: Development and validation of an acute kidney injury risk index for patients undergoing general surgery: results from a national data set. Anesthesiology 2009;110:505515.

17 Ghaferi AA, Birkmeyer JD, Dimick JB: Variation in hospital mortality associated with inpatient surgery. N Engl J Med 2009;361:13681375 .

18 Korenkevych D, Ozrazgat-Baslanti T, Thottakkara P, Hobson CE, Pardalos P, Momcilovic $\mathrm{P}$, Bihorac A: The pattern of longitudinal change in serum creatinine and 90-day mortality after major surgery. Ann Surg 2015, Epub ahead of print.

19 Zeng X, McMahon GM, Brunelli SM, Bates DW, Waikar SS: Incidence, outcomes, and comparisons across definitions of AKI in hospitalized individuals. Clin J Am Soc Nephrol 2014;9:12-20.

20 Sileanu FE, Murugan R, Lucko N, Clermont G, Kane-Gill SL, Handler SM, Kellum JA: AKI in low-risk versus high-risk patients in intensive care. Clin J Am Soc Nephrol 2015; 10 : 187-196.

21 Hobson C, Ozrazgat-Baslanti T, Kuxhausen A, Thottakkara P, Efron PA, Moore FA, Moldawer LL, Segal MS, Bihorac A: Cost and mortality associated with postoperative acute kidney injury. Ann Surg 2014

22 Brienza N, Giglio MT, Marucci M, Fiore T: Does perioperative hemodynamic optimization protect renal function in surgical patients? A meta-analytic study. Crit Care Med 2009;37:2079-2090.
23 Reich DL, Hossain S, Krol M, Baez B, Patel P, Bernstein A, Bodian CA: Predictors of hypotension after induction of general anesthesia. Anesth Analg 2005;101:622-628.

24 Aitken E, Carruthers C, Gall L, Kerr L, Geddes C, Kingsmore D: Acute kidney injury: outcomes and quality of care. QJM 2013;106: 323-332.

25 Thakar CV: Perioperative acute kidney injury. Adv Chronic Kidney Dis 2013;20:67-75.

26 Huen SC, Parikh CR: Predicting acute kidney injury after cardiac surgery: a systematic review. Ann Thorac Surg 2012;93:337-347.

27 Borthwick E, Ferguson A: Perioperative acute kidney injury: risk factors, recognition, management, and outcomes. BMJ 2010;341:c3365.

28 Kashani K, Al-Khafaji A, Ardiles T, Artigas A, Bagshaw SM, Bell M, Bihorac A, Birkhahn R, Cely CM, Chawla LS, Davison DL, Feldkamp T, Forni LG, Gong MN, Gunnerson KJ, Haase M, Hackett J, Honore PM, Hoste EA, JoannesBoyau O, Joannidis M, Kim P, Koyner JL, Laskowitz DT, Lissauer ME, Marx G, McCullough PA, Mullaney S, Ostermann M, Rimmelé T, Shapiro NI, Shaw AD, Shi J, Sprague AM, Vincent JL, Vinsonneau C, Wagner L, Walker MG, Wilkerson RG, Zacharowski K, Kellum JA: Discovery and validation of cell cycle arrest biomarkers in human acute kidney injury. Crit Care 2013;17:R25.

29 Bihorac A, Chawla LS, Shaw AD, Al-Khafaji A, Davison DL, Demuth GE, Fitzgerald R, Gong MN, Graham DD, Gunnerson K, Heung M, Jortani S, Kleerup E, Koyner JL, Krell K, Letourneau J, Lissauer M, Miner J, Nguyen HB, Ortega LM, Self WH, Sellman R, Shi J, Straseski J, Szalados JE, Wilber ST, Walker MG, Wilson J, Wunderink R, Zimmerman J, Kellum JA: Validation of cell-cycle arrest biomarkers for acute kidney injury using clinical adjudication. Am J Respir Crit Care Med 2014;189:932-939.

30 Bihorac A, Korenkevych D, Ozrazgat Baslanti T, Momcilovic P, Pardalos P, Segal MS, Moore FA: Database communication enables machine learning classifiers to predict postoperative acute kidney injury. Crit Care Med 2013;41:714. 